\title{
A Comparative study on structural, morphological and photocatalytic properties of anodically grown ZnO nanowires under varying parameters
}

\section{Erdem Tevfik Ozdemir}

Dokuz Eylul University: Dokuz Eylul Universitesi

Uğur KARTAL ( $\nabla$ ugurkartal@iyte.edu.tr)

Dokuz Eylul Universitesi Muhendislik Fakultesi https://orcid.org/0000-0002-5557-2300

Tuncay Dikici

Dokuz Eylul University: Dokuz Eylul Universitesi

\section{Mustafa Erol}

Dokuz Eylul University: Dokuz Eylul Universitesi

\section{Metin Yurddaskal}

Dokuz Eylul University: Dokuz Eylul Universitesi

\section{Research Article}

Keywords: Nanowire, photocatalyst, degradation, ZnO, anodization

Posted Date: May 4th, 2021

DOl: https://doi.org/10.21203/rs.3.rs-479424/v1

License: (9) This work is licensed under a Creative Commons Attribution 4.0 International License.

Read Full License

Version of Record: A version of this preprint was published at Journal of Materials Science: Materials in Electronics on September 29th, 2021. See the published version at https://doi.org/10.1007/s10854-02107115-7. 


\title{
A Comparative study on structural, morphological and photocatalytic properties of anodically grown $\mathrm{ZnO}$ nanowires under varying parameters
}

Erdem Tevfik Ozdemir ${ }^{1}$, Ugur Kartal $^{2 *}$, Tuncay Dikici ${ }^{3,4}$, Mustafa Erol $^{4,5}$, Metin Yurddaskal ${ }^{5}$

\author{
${ }^{1}$ The Graduate School of Natural and Sciences, Dokuz Eylul University, Izmir, Turkey \\ ${ }^{2}$ Department of Materials Science and Engineering, Izmir Institute of Technology, Izmir, Turkey \\ ${ }^{3}$ Torbali Vocational School, Dokuz Eylul University, Izmir, Turkey \\ ${ }^{4}$ Center for Fabrication and Application of Electronic Materials, Dokuz Eylul University, Izmir, Turkey \\ ${ }^{5}$ Department of Metallurgical and Materials Engineering, Dokuz Eylul University, Izmir, Turkey
}

\begin{abstract}
In this study, Zinc oxide ( $\mathrm{ZnO})$ nanowires (NWs) were successfully produced on $\mathrm{Zn}$ plates through electrochemical anodization in potassium bicarbonate aqueous electrolytes with different production parameters in two groups as applied voltage and anodization time. Subsequently, the $\mathrm{ZnO}$ NWs were annealed at $300{ }^{\circ} \mathrm{C}$ for $1 \mathrm{~h}$ in air atmosphere to increase crystallinity and remove organic residues. Structural and morphological properties were determined through X-ray diffraction (XRD) and scanning electron microscopy (SEM) analysis. The effect of anodization parameters on the structure of $\mathrm{ZnO} \mathrm{NWs}$ and thus their photocatalytic activities were evaluated in detail by UV spectrophotometer. The results pointed out that, the most effective nanostructure on the photocatalytic degradation of methylene blue was obtained at the sample anodized under $30 \mathrm{~V}$ for $30 \mathrm{~min}$ at room temperature with $90.6 \%$ degradation efficiency among the samples. This result shows that the NW structured $\mathrm{ZnO}$ materials are promising to be used as effective photocatalysts in the removal of organic pollutants by solar energy and their conversion to green compounds.
\end{abstract}

Keywords: Nanowire, photocatalyst, degradation, $\mathrm{ZnO}$, anodization

Corresponding Author: ugurkartal@iyte.edu.tr (Ugur KARTAL) 


\section{Introduction}

Semiconductors are environmentally friendly materials that have a wide range of daily applications and do not pose major environmental risks. The metal oxide semiconductors ( $\mathrm{ZnO}$, $\mathrm{TiO}_{2}, \mathrm{Fe}_{2} \mathrm{O}_{3}, \mathrm{CuO}, \mathrm{NiO}$, etc.), have favorable properties that desired in a variety of applications [1]. One of these applications is photocatalysis and some semiconductors, such as $\mathrm{TiO}_{2}$ and $\mathrm{ZnO}$, are heavily utilized for the degradation of environmental contaminants [2-5]. Photocatalysis, also known as photo-assisted catalysis, has processes similar to photosynthesis [3]. When photons with energies greater than the band gap energy of the photocatalyst are absorbed, at least two reactions occur simultaneously and carbon dioxide and water come out of dissolution of various organic compounds [6]. After publication of Fujishima and Honda on photocatalytic water splitting via $\mathrm{TiO}_{2}$ in 1972, studies on $\mathrm{TiO}_{2}$ as a photocatalyst have increased considerably [7]. Although the $\mathrm{TiO}_{2}$ photocatalyst is widely used, $\mathrm{ZnO}$ is a feasible alternative to be photocatalyst because of its band gap energy and its relatively lower cost of production $[8,9]$.

$\mathrm{ZnO}$ is a n-type semiconductor that has been receiving a great attention in the last decade [5]. $\mathrm{ZnO}$, with a wide band gap (3.37 eV) and large exciton binding energy (60 meV) [10-13], has found a wide range of possible applications in photocatalysis [14], photovoltaics [15], lightemitting diodes [16], sensing [17] and many others [18].

One-dimensional (1D) nanostructures have been studied affluently due to their high charge transport efficiency and surface to volume ratio [19]. ZnO nanowires (NWs) is the most engaging nanostructures of $\mathrm{ZnO}$. Up to now, several different synthesis methods to fabricate $\mathrm{ZnO} \mathrm{NWs}$ have been used in the literature, e.g., hydrothermal methods [20], chemical vapor deposition [21], template-directed methods [22], sol-gel [11], molecular beam epitaxy [23], atomic layer deposition [24], pulsed laser deposition [25], or direct precipitation [26]. Nonetheless, most of these methods required long reaction times, expensive experimental setups and complicated procedures.

Apart from aforementioned methods, electrochemical anodization is a promising method as efficient, highly controllable, fast and cost effective. This process has gained much attention after demonstration of two-step approach by Masuda and Fukuda in 1995 [27]. The oxidizing of a surface of an anode metal is provided through electrochemical anodization method, in a specific electrolyte under a specific voltage at room temperature, resulting in the formation of various nanostructured materials e.g., nanoporous-like structures, nanoflakes, nanoflowers, nanoneedles and NWs $[1,28,29]$. It is obvious that bicarbonate solutions are very popular electrolytes for anodizing of $\mathrm{Zn}$ to obtain $\mathrm{ZnO}$ NWs [30]. The conditions such as applied during 
anodic oxidation, including electrolyte concentration, applied potential, temperature and duration of the process, have a profound effect on the physical and chemical properties of the NWs [12].

In this context, $\mathrm{ZnO}$ NWs have been prepared on $\mathrm{Zn}$ plate by electrochemical anodizing technique under different production parameters such as applied voltage and anodization time. The phase structures, surface morphologies and photocatalytic activities of $\mathrm{ZnO}$ NWs were examined in detail.

\section{Experimental studies}

\subsection{Materials}

Zn plate $(99.9 \%$, thickness $1 \mathrm{~mm})$ was supplied by BByes Store. Potassium bicarbonate $\left(\mathrm{KHCO}_{3}, 99.7 \%\right)$, absolute ethanol $\left(\mathrm{C}_{2} \mathrm{H}_{5} \mathrm{OH}, \geq 99.9\right)$, isopropyl alcohol $\left(\mathrm{C}_{3} \mathrm{H}_{8} \mathrm{O}, 99.5 \%\right)$ were supplied from Merck and used as purchased.

\subsection{Synthesis of ZnO NWs}

Anodization samples of $25 \times 25 \mathrm{~mm}^{2}$ dimensions were cut from $\mathrm{Zn}$ plate. Subsequently, the $\mathrm{Zn}$ substrates were washed with $\mathrm{C}_{2} \mathrm{H}_{5} \mathrm{OH}$ and distilled water in an ultrasonic cleaner (Everest CleanEx-2511) for $15 \mathrm{~min}$, respectively. Cleaned substrates were dried at room temperature in the air atmosphere. Applied anodization parameters to the $\mathrm{Zn}$ substrates were categorized and listed in Table 1. Anodization was performed under different voltages (10-40 V) and anodization times (10-120 $\mathrm{min}$ ) for investigating the anodization parameters on the structure of produced $\mathrm{ZnO}$ which has a certain effect on the photocatalytic activity. For anodization process, two-electrode electrochemical cell setup (Fig. 1) containing Zn plate as a working electrode, stainless steel plate as a counter electrode and aqueous solution of $\mathrm{KHCO}_{3}(50 \mathrm{mM})$ as an electrolyte was used. The distance between two electrodes was kept at $10 \mathrm{~cm}$ through anodization process. The anodized samples were rinsed with distilled water and $\mathrm{C}_{3} \mathrm{H}_{8} \mathrm{O}$ to remove remaining electrolyte, respectively. Afterward, the samples were put in a drying oven (Binder ED53) at $80{ }^{\circ} \mathrm{C}$ for $60 \mathrm{~min}$. Finally, the as-anodized samples were annealed at a temperature of $300{ }^{\circ} \mathrm{C}$ for $1 \mathrm{~h}$ at the heating rate of $2{ }^{\circ} \mathrm{C} \mathrm{min}^{-1}$ and stored in a desiccator before characterization. 
Table 1 Anodization parameters of $\mathrm{ZnO}$ NWs

\begin{tabular}{cccc}
\hline Group & Sample Code & Voltage (V) & Time (min) \\
\hline \multirow{4}{*}{ Group 1 } & S1 & 10 & 30 \\
& S2 & 20 & 30 \\
& S3 & 30 & 30 \\
& S4 & 40 & 30 \\
\hline \multirow{6}{*}{ Group 2 } & S5 & 10 & 10 \\
& S6 & 10 & 20 \\
& S7 & 10 & 60 \\
& S8 & 10 & 120 \\
\hline
\end{tabular}

\subsection{Materials Characterization}

In order to elucidate the phase structure, as-anodized and annealed samples were examined by an X-ray diffractometer (XRD, Thermo Scientific ARL X'TRA) with a Cu-Ka (1.54185 $\AA)$ irradiation in the range of $2 \theta=10-90^{\circ}$ at the scan rate of $2 \% \mathrm{~min}$. The surface morphology and nanostructure of the samples were observed by a scanning electron microscope (SEM, Carl Zeiss 300VP).

\subsection{Photocatalytic Measurements}

The photocatalytic activities of the samples were scrutinized by using $10^{-5} \mathrm{M}$ of methylene blue (MB) solution under 300W Osram Ultra-Vitalux E27 (4.53\% UVA, 1\% UVB, 94.47\% Vis) light source at room temperature. In order to compare catalyst-free degradation of MB under irradiation a reference solution was also prepared. The photocatalysts were immersed into 30 $\mathrm{mL}$ of $\mathrm{MB}$ aqueous solution in beakers and placed under the light source with a distance approximately $20 \mathrm{~cm}$. In order to determine the absorbencies, $3 \mathrm{ml}$ of the MB solution from each beaker was taken out at given time intervals after UV light exposure. The absorption measurements of the MB solution were performed at the wavelength from $400 \mathrm{~nm}$ to $800 \mathrm{~nm}$ and confirmed by monitoring the decreasing of absorbance at $664 \mathrm{~nm}$, which is the characteristic peak of MB, by a UV spectrophotometer (Shimadzu UV 1240 spectrophotometer) [31]. Within the scope of Lambert Beer Law, the absorbance values were converted to concentration values [32]. Their photocatalytic degradation efficiency was defined as $\left[\left(\mathrm{C}_{0}-\mathrm{C}\right) / \mathrm{C}_{0}\right] \times 100\left(\mathrm{C}_{0}\right.$; initial concentration, $\mathrm{C}$; final concentration). For the final step of characterization, photocatalytic reaction kinetics on MB degradation were calculated for all samples using the catalysts. 


\section{Results and discussion}

\subsection{Structural Analysis}

The structures of the as-anodized and annealed $\mathrm{ZnO}$ NWs were analyzed via the XRD technique. The XRD patterns of $\mathrm{ZnO} \mathrm{NWs}$ which produced at different voltages and anodization time by electrochemical anodization method were shown in Fig. $2 \mathrm{a}$ and $2 \mathrm{~b}$ for sample groups 1 and 2, respectively. It was observed from these patterns, the samples were mixed form of metallic $\mathrm{Zn}$ and wurtzite phases as marked with 1 and 2 for $\mathrm{Zn}$ (ICDD 03-0655973) and wurtzite (ICDD 00-036-1451), respectively [1]. Note that the peaks (1) metallic Zn were arised from Zn substrates in all patterns. As shown in Fig. 2a and 2b, the peak intensities of the $\mathrm{ZnO}$ structures were augmented with the rising of applied voltage and anodization time. The structural data of the samples were found to be convenient to the literature $[1,10,33]$.

\subsection{Morphological Analysis}

Fig. 3 shows the surface images of the $\mathrm{ZnO}$ NWs were obtained at different voltages such as 10, 20, 30 and $40 \mathrm{~V}$. As seen in the Fig. 3a, the nanoflower structures formed at an initial point of growth transformed to aligned NW structures. ZnO NWs have become thinner and denser structures with increasing voltage. When the applied voltage is $40 \mathrm{~V}$, there were linked and interpenetrated structures due to the length of the NWs as seen in Fig. 3d. Furthermore, micro cracks were observed on the surface due to oxygen evaluation during anodization at high voltage. Fig. 4 indicates the effects of anodizing time on the morphology of $\mathrm{ZnO}$ NWs. The results show that as the anodizing time increases, the thickness of the $\mathrm{ZnO}$ NWs decreases while the density increases. The hierarchical $\mathrm{ZnO}$ NWs structure has emerged after anodization for $60 \mathrm{~min}$. As seen in literature, these results are in good agreement with the previously published studies $[19,28,30]$.

\subsection{Photocatalytic Activity}

The photocatalytic mechanism of $\mathrm{ZnO}$ NWs with different morphological properties was shown in Fig. 5. Due to the light excitation of $\mathrm{ZnO}$, holes $\left(\mathrm{h}^{+}\right)$are formed in the valence band, while electrons $\left(\mathrm{e}^{-}\right)$are transferred to the conduction band. Thus, when oxygen molecules $\left(\mathrm{O}_{2}\right)$ are excited by light, they form super oxide radical anions $\left(\bullet \mathrm{O}_{2}{ }^{-}\right)$. These $\mathrm{O}_{2}$ 's degrade $\mathrm{MB}$ into green compounds such as carbon dioxide $\left(\mathrm{CO}_{2}\right)$ and water $\left(\mathrm{H}_{2} \mathrm{O}\right)$. The reactions that occur during the degradation of MB under UV light source can be listed as follows: 


$$
\begin{aligned}
& \mathrm{ZnO}+\mathrm{hv} \longrightarrow{\mathrm{ZnO}\left(\mathrm{h}^{+}+\mathrm{e}^{-}\right)}^{\mathrm{O}_{2}+\mathrm{e}^{-} \longrightarrow \mathrm{O}_{2}^{-}} \\
& \mathrm{H}_{2} \mathrm{O}+\mathrm{h}^{+} \longrightarrow \cdot \mathrm{OH}+\mathrm{H}^{+} \\
& \mathrm{h}^{+}+\cdot \mathrm{O}_{2}^{-}+\cdot \mathrm{OH}+\mathrm{MB} \longrightarrow \mathrm{CO}_{2}+\mathrm{H}_{2} \mathrm{O}
\end{aligned}
$$

The photocatalytic performances of the samples were obtained by measuring the absorbance data of the samples taken from the degraded MB at certain time intervals. The MB aqueous solution under UV-Vis light irradiation is degraded by photocatalysts thanks to the photocatalytic effect. Concentration data were obtained using the Lambert-Beer law from the absorbance values at $664 \mathrm{~nm}$ which is the characteristic peak of MB. Fig. 6a shows the change in concentration of MB over 11 hours. The degradation efficiency, kinetic rate constant and determination coefficient parameters of the samples are given in Table 2. The k values obtained from the slope of the lines in Fig. $6 \mathrm{~b}$ show that the most enhanced photocatalytic degradation of MB was obtained with the S3 sample. The k values obtained showed that the photocatalytic degradation of MB correlated with the anodizing parameters. As the surface morphology and dimensions of the structure change with changing anodizing parameters, the photocatalytic performance also changes in relation to this. The photocatalytic degradation rate was calculated for all samples using Eq. 5:

$\ln \frac{C_{0}}{C}=k t$

where $\mathrm{C}_{0}, \mathrm{C}$ and $\mathrm{t}$ are the initial concentration of $\mathrm{MB}$, the concentration of $\mathrm{MB}$ at certain time and irradiation time, respectively.

Table 2 Photocatalytic parameters of the $\mathrm{ZnO}$ NW structured samples

\begin{tabular}{lccccccccc}
\hline \multirow{2}{*}{ Samples } & \multicolumn{1}{c}{ Group 1 } & \multicolumn{5}{c}{ Group 2 } \\
\cline { 2 - 9 } & Ref. & S1 & S2 & S3 & S4 & S5 & S6 & S7 & S8 \\
\hline $\begin{array}{l}\text { Degradation } \\
\text { efficiency (\%) }\end{array}$ & 21.8 & 80.4 & 86.3 & 90.6 & 88.3 & 86.6 & 84.6 & 77.9 & 83.8 \\
\hline $\begin{array}{l}\text { Kinetic rate } \\
\text { constant (k) } \\
\left(\mathbf{1 0}^{-3} \mathbf{m i n}^{-\mathbf{1}}\right)\end{array}$ & 0.374 & 2.471 & 3.015 & 3.590 & 3.256 & 3.047 & 2.835 & 2.225 & 2.765 \\
\hline $\mathbf{R}^{\mathbf{2}}$ & 0.992 & 0.992 & 0.983 & 0.988 & 0.994 & 0.99 & 0.980 & 0.996 & 0.986 \\
\hline
\end{tabular}


Many factors such as nanostructure, surface area, crystallinity, phase composition, crystal orientation and structure dimensions affect photocatalytic performance. The degradation efficiencies of MB with an initial absorbance value of 0.695 at $664 \mathrm{~nm}$ by different samples were calculated for each sample. The results obtained are given in Table 2 and shown as a bar graph in Fig. 7. As can be seen from Fig. 7, the degradation efficiency after 11 hours for the arbitration sample is $21.8 \%$ while it is $90.6 \%$ for the $\mathrm{S} 3$ sample. With this degradation efficiency value, the S3 sample has the best photocatalytic performance. It is thought that the reason for the S3 sample having the best photocatalytic activity is that the surface morphology is densely composed of thin and long NW and the high surface area obtained due to the presence of these NWs independently from each other. As a result, photocatalysts with different photocatalytic activity values can be obtained by controlling the anodization time and voltage, which have significant effects on the surface area.

Absorption spectra of MB for sample S3 were drawn for different durations and are shown in Fig. 8. MB was degraded under UV-Vis light source using S3 sample for 11 hours. The absorbance value of MB at $664 \mathrm{~nm}$, which was kept under UV-Vis light illumination for 11 hours, was reduced from 0.695 to 0.065 with the degradation efficiency of $90.6 \%$ in the presence of the $\mathrm{S} 3$ sample.

\section{CONCLUSION}

In summary, $\mathrm{ZnO}$ NWs were successfully formed on $\mathrm{Zn}$ plates using facile electrochemical anodization method in potassium bicarbonate aqueous electrolytes at different anodizing parameters. The structural characteristics of the $\mathrm{ZnO}$ NWs can be controlled by various growth parameters. The obtained SEM results reveal that $\mathrm{ZnO}$ NWs have become thinner and denser structures with increasing applied voltage and anodization time. Furthermore, cracking on the surfaces happened at voltages over $30 \mathrm{~V}$ due to oxygen evolution. In addition to the structural results the hierarchical $\mathrm{ZnO} N W s$ structure has emerged after anodization for $60 \mathrm{~min}$. On the basis of these photocatalysts, the highest photocatalytic efficiency with $90.6 \%$ belongs to the sample anodized at $30 \mathrm{~V}$ for $30 \mathrm{~min}$. This result shows that $\mathrm{NW}$ structured $\mathrm{ZnO}$ materials are promising that they can be used as effective photocatalysts in the conversion of organic pollutants by solar energy into green compounds.

\section{REFERENCES}

[1] A. Yavaş, S. Güler, M. Erol, Growth of $\mathrm{ZnO}$ nanoflowers: effects of anodization time 
and substrate roughness on structural, morphological, and wetting properties, J. Aust. Ceram. Soc. 56 (2020) 995-1003. https://doi.org/10.1007/s41779-019-00440-5.

[2] M. Erol, T. Dikici, M. Toparli, E. Celik, The effect of anodization parameters on the formation of nanoporous $\mathrm{TiO}_{2}$ layers and their photocatalytic activities, J. Alloys Compd. 604 (2014) 66-72. https://doi.org/10.1016/j.jallcom.2014.03.105.

[3] D.F. Ollis, Photocatalytic purification and remediation of contaminated air and water, Comptes Rendus 1'Academie Des Sci. - Ser. IIc Chem. 3 (2000) 405-411. https://doi.org/10.1016/S1387-1609(00)01169-5.

[4] R.Y. Hong, J.H. Li, L.L. Chen, D.Q. Liu, H.Z. Li, Y. Zheng, J. Ding, Synthesis, surface modification and photocatalytic property of $\mathrm{ZnO}$ nanoparticles, Powder Technol. 189 (2009) 426-432. https://doi.org/10.1016/j.powtec.2008.07.004.

[5] K.M. Lee, C.W. Lai, K.S. Ngai, J.C. Juan, Recent developments of zinc oxide based photocatalyst in water treatment technology: A review, Water Res. 88 (2016) 428-448. https://doi.org/10.1016/j.watres.2015.09.045.

[6] A. Fujishima, X. Zhang, D.A. Tryk, $\mathrm{TiO}_{2}$ photocatalysis and related surface phenomena, Surf. Sci. Rep. 63 (2008) 515-582. https://doi.org/10.1016/j.surfrep.2008.10.001.

[7] A. Fujishima, K. Honda, Electrochemical photolysis of water at a semiconductor electrode, Nature. 238 (1972) 37-38. https://doi.org/10.1038/238037a0.

[8] D.M. Fouad, M.B. Mohamed, Comparative study of the photocatalytic activity of semiconductor nanostructures and their hybrid metal nanocomposites on the $\begin{array}{llllll}\text { photodegradation of malathion, J. Nanomater. } 2012 & \text { (2012). }\end{array}$ https://doi.org/10.1155/2012/524123.

[9] Y.J. Jang, C. Simer, T. Ohm, Comparison of zinc oxide nanoparticles and its nanocrystalline particles on the photocatalytic degradation of methylene blue, Mater. Res. Bull. 41 (2006) 67-77. https://doi.org/10.1016/j.materresbull.2005.07.038.

[10] Z. Hu, Q. Chen, Z. Li, Y. Yu, L.M. Peng, Large-scale and rapid synthesis of ultralong $\mathrm{ZnO}$ nanowire films via anodization, J. Phys. Chem. C. 114 (2010) 881-889. https://doi.org/10.1021/jp9094744.

[11] S.E. Ahn, J.L. Soo, H. Kim, S. Kim, B.H. Kang, K.H. Kim, G.T. Kim, Photoresponse of sol-gel-synthesized $\mathrm{ZnO}$ nanorods, Appl. Phys. Lett. 84 (2004) 5022-5024. https://doi.org/10.1063/1.1763633.

[12] L. Zaraska, K. Mika, K. Syrek, G.D. Sulka, Formation of ZnO nanowires during anodic oxidation of zinc in bicarbonate electrolytes, J. Electroanal. Chem. 801 (2017) 511-520. https://doi.org/10.1016/j.jelechem.2017.08.035. 
[13] J. Dong, Z. Liu, J. Dong, D. Ariyanti, Z. Niu, S. Huang, W. Zhang, W. Gao, Selforganized $\mathrm{ZnO}$ nanorods prepared by anodization of zinc in $\mathrm{NaOH}$ electrolyte, RSC Adv. 6 (2016) 72968-72974. https://doi.org/10.1039/c6ra16995c.

[14] C. Tian, Q. Zhang, A. Wu, M. Jiang, B. Jiang, H. Fu, Cost-effective large-scale synthesis of $\mathrm{ZnO}$ photocatalyst with excellent performance for dye photodegradation, Chem. Commun. 48 (2012) 2858-2860. https://doi.org/10.1039/c2cc16434e.

[15] R. Kumar, A. Umar, G. Kumar, H.S. Nalwa, A. Kumar, M.S. Akhtar, Zinc oxide nanostructure-based dye-sensitized solar cells, J. Mater. Sci. 52 (2017) 4743-4795. https://doi.org/10.1007/s10853-016-0668-z.

[16] A. Achour, M.A. Soussou, K. Ait Aissa, M. Islam, N. Barreau, E. Faulques, L. Le Brizoual, M.A. Djouadi, M. Boujtita, Nanostructuration and band gap emission enhancement of $\mathrm{ZnO}$ film via electrochemical anodization, Thin Solid Films. 571 (2014) 168-174. https://doi.org/10.1016/j.tsf.2014.10.061.

[17] N. Tiwale, Zinc oxide nanowire gas sensors: Fabrication, functionalisation and devices, Mater. Sci. Technol. (United Kingdom). 31 (2015) 1681-1697. https://doi.org/10.1179/1743284714Y.0000000747.

[18] Y. Zhang, M.K. Ram, E.K. Stefanakos, D.Y. Goswami, Synthesis, characterization, and applications of $\mathrm{ZnO}$ nanowires, J. Nanomater. (2012). https://doi.org/10.1155/2012/624520.

[19] A. Mateen Tantray, M.A. Shah, Photo electrochemical ability of dense and aligned ZnO nanowire arrays fabricated through electrochemical anodization, Chem. Phys. Lett. 747 (2020) 137346. https://doi.org/10.1016/j.cplett.2020.137346.

[20] J.Y. Kim, J.W. Cho, S.H. Kim, The characteristic of the $\mathrm{ZnO}$ nanowire morphology grown by the hydrothermal method on various surface-treated seed layers, Mater. Lett. 65 (2011) 1161-1164. https://doi.org/10.1016/j.matlet.2010.10.092.

[21] J.L. Yang, S.J. An, W. Il Park, G.C. Yi, W. Choi, Photocatalysis using ZnO thin films and nanoneedles grown by metal-organic chemical vapor deposition, Adv. Mater. 16 (2004) 1661-1664. https://doi.org/10.1002/adma.200306673.

[22] Y.H. Chen, Y.M. Shen, S.C. Wang, J.L. Huang, Fabrication of one-dimensional ZnO nanotube and nanowire arrays with an anodic alumina oxide template via electrochemical deposition, Thin Solid Films. 570 (2014) 303-309. https://doi.org/10.1016/j.tsf.2014.03.014.

[23] A. Menzel, K. Subannajui, R. Bakhda, Y. Wang, R. Thomann, M. Zacharias, Tuning the growth mechanism of $\mathrm{ZnO}$ nanowires by controlled carrier and reaction gas modulation 
in thermal CVD, J. Phys. Chem. Lett. 3 (2012) 2815-2821. https://doi.org/10.1021/jz301103s.

[24] K. Subannajui, F. Güder, J. Danhof, A. Menzel, Y. Yang, L. Kirste, C. Wang, V. Cimalla, U. Schwarz, M. Zacharias, An advanced fabrication method of highly ordered $\mathrm{ZnO}$ nanowire arrays on silicon substrates by atomic layer deposition, Nanotechnology. 23 (2012) 7. https://doi.org/10.1088/0957-4484/23/23/235607.

[25] C. Florica, N. Preda, A. Costas, I. Zgura, I. Enculescu, ZnO nanowires grown directly on zinc foils by thermal oxidation in air: Wetting and water adhesion properties, Mater. Lett. 170 (2016) 156-159. https://doi.org/10.1016/j.matlet.2016.02.035.

[26] J. Huang, H. Ren, P. Sun, C. Gu, Y. Sun, J. Liu, Facile synthesis of porous ZnO nanowires consisting of ordered nanocrystallites and their enhanced gas-sensing property, Sensors Actuators, B Chem. $188 \quad$ (2013) 249-256. https://doi.org/10.1016/j.snb.2013.06.103.

[27] H. Masuda, K. Fukuda, Ordered metal nanohole arrays made by a two-step replication of honeycomb structures of anodic alumina, Science (80-. ). 268 (1995) 1466-1468. https://doi.org/10.1126/science.268.5216.1466.

[28] D.O. Miles, P.J. Cameron, D. Mattia, Hierarchical 3D ZnO nanowire structures via fast anodization of zinc, J. Mater. Chem. A. 3 (2015) 17569-17577. https://doi.org/10.1039/c5ta03578c.

[29] A. Ramirez-canon, D.O. Miles, J. Cameron, D. Mattia, Zinc oxide nanostructured films via anodization: a rational design approach $\dagger$ (2013) 25323-25330. https://doi.org/10.1039/c3ra43886d.

[30] L. Zaraska, K. Mika, M. Zych, G.D. Sulka, Anodic formation of zinc oxide nanostructures with various morphologies, INC, 2020. https://doi.org/10.1016/b978-012-816706-9.00012-1.

[31] M.U. Anu Prathap, B. Kaur, R. Srivastava, Hydrothermal synthesis of CuO micro/nanostructures and their applications in the oxidative degradation of methylene blue and non-enzymatic sensing of glucose/ $\mathrm{H}_{2} \mathrm{O}_{2}$, J. Colloid Interface Sci. 370 (2012) 144-154. https://doi.org/10.1016/j.jcis.2011.12.074.

[32] S. Demirci, T. Dikici, M. Yurddaskal, S. Gultekin, M. Toparli, E. Celik, Synthesis and characterization of $\mathrm{Ag}$ doped $\mathrm{TiO}_{2}$ heterojunction films and their photocatalytic performances, Appl. Surf. Sci. $390 \quad$ (2016) 591-601. https://doi.org/10.1016/j.apsusc.2016.08.145.

[33] Y.T. Kim, J. Park, S. Kim, D.W. Park, J. Choi, Fabrication of hierarchical ZnO 
nanostructures for dye-sensitized solar cells, Electrochim. Acta. 78 (2012) 417-421. https://doi.org/10.1016/j.electacta.2012.06.022. 
Figures

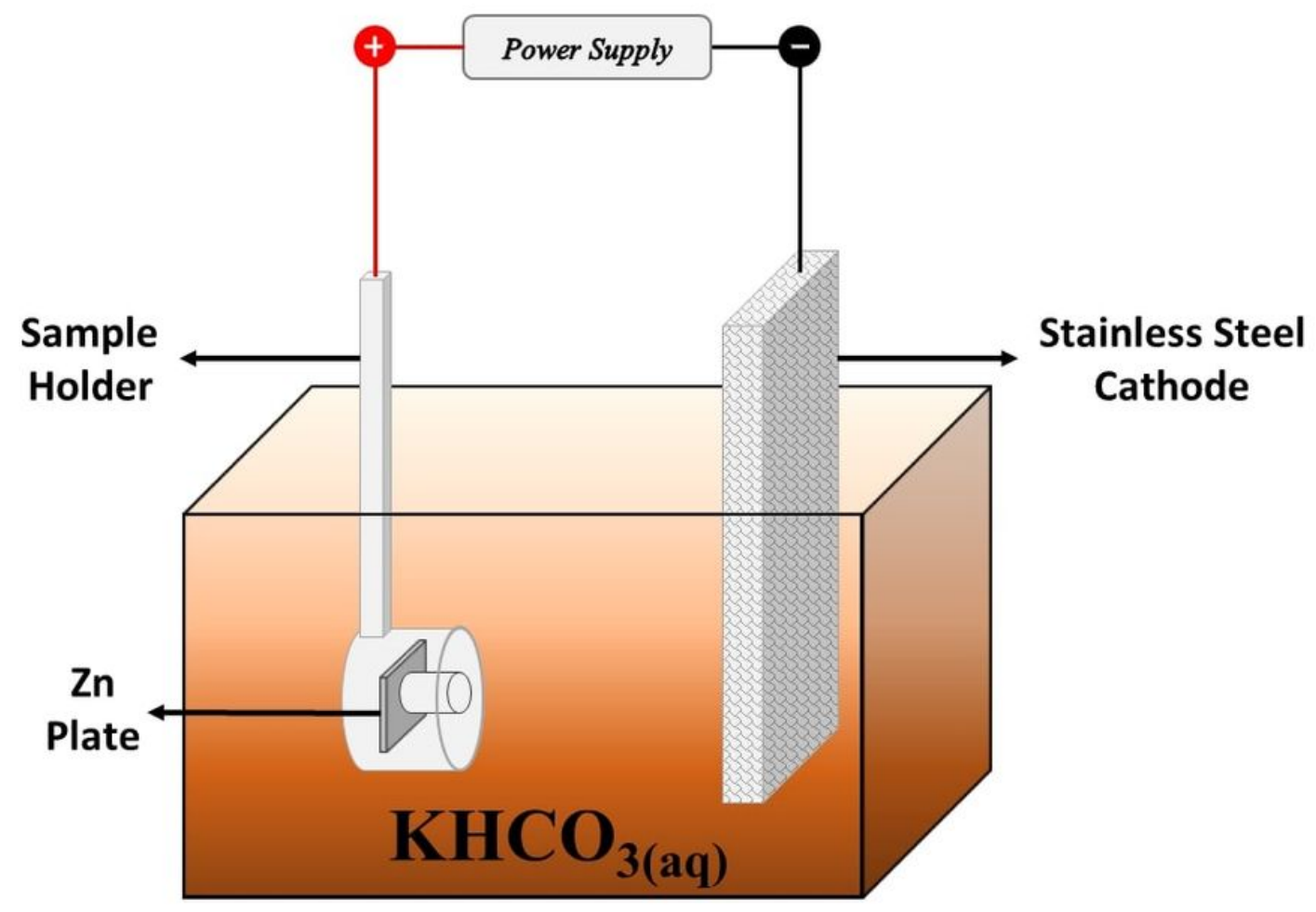

\section{Figure 1}

For anodization process, two-electrode electrochemical cell setup (Fig. 1) containing Zn plate as a working electrode, stainless steel plate as a counter electrode and aqueous solution of KHCO3 (50 mM) as an electrolyte was used. 

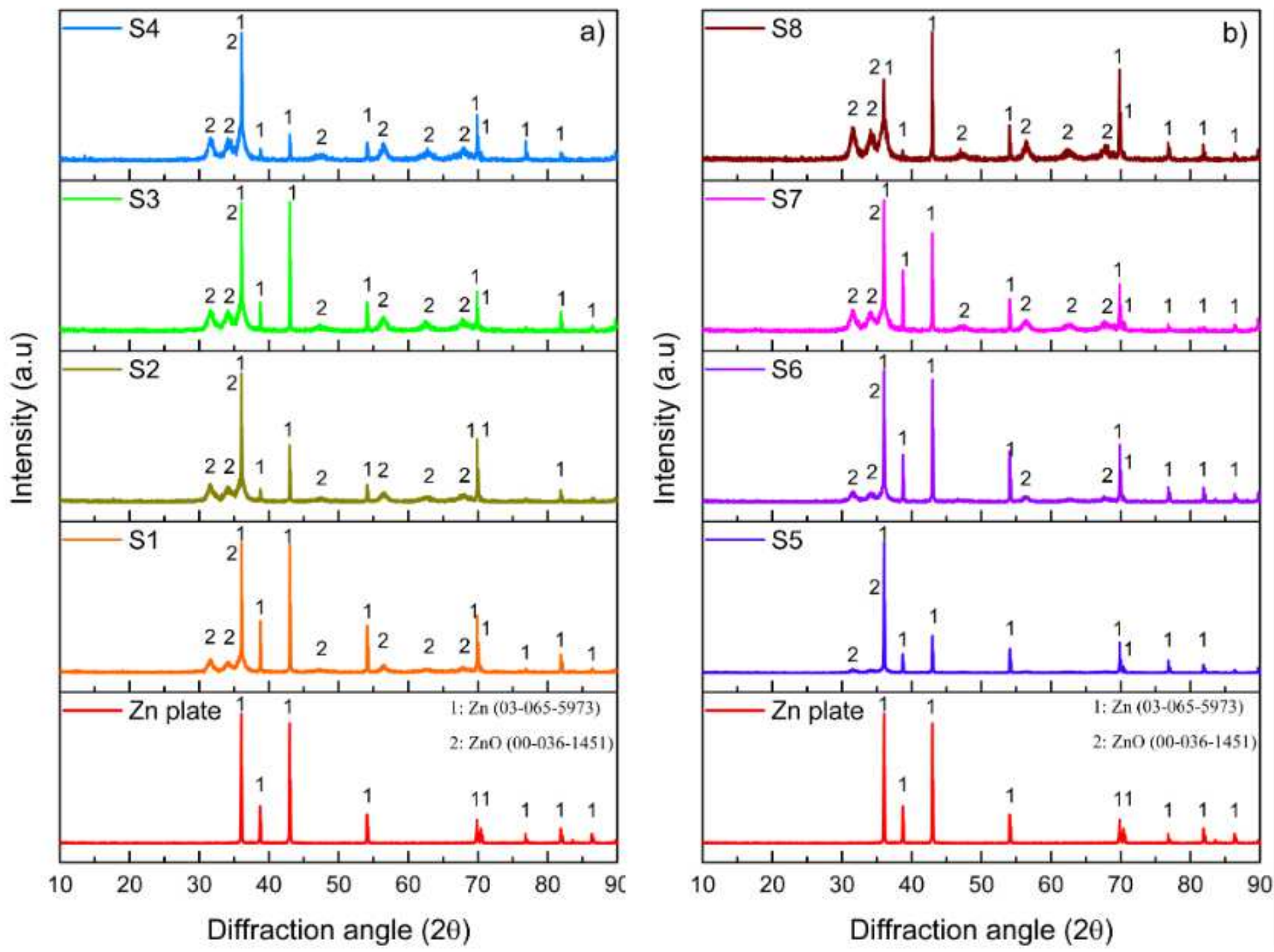

Figure 2

As shown in Fig. $2 \mathrm{a}$ and $2 \mathrm{~b}$, the peak intensities of the $\mathrm{ZnO}$ structures were augmented with the rising of applied voltage and anodization time. 

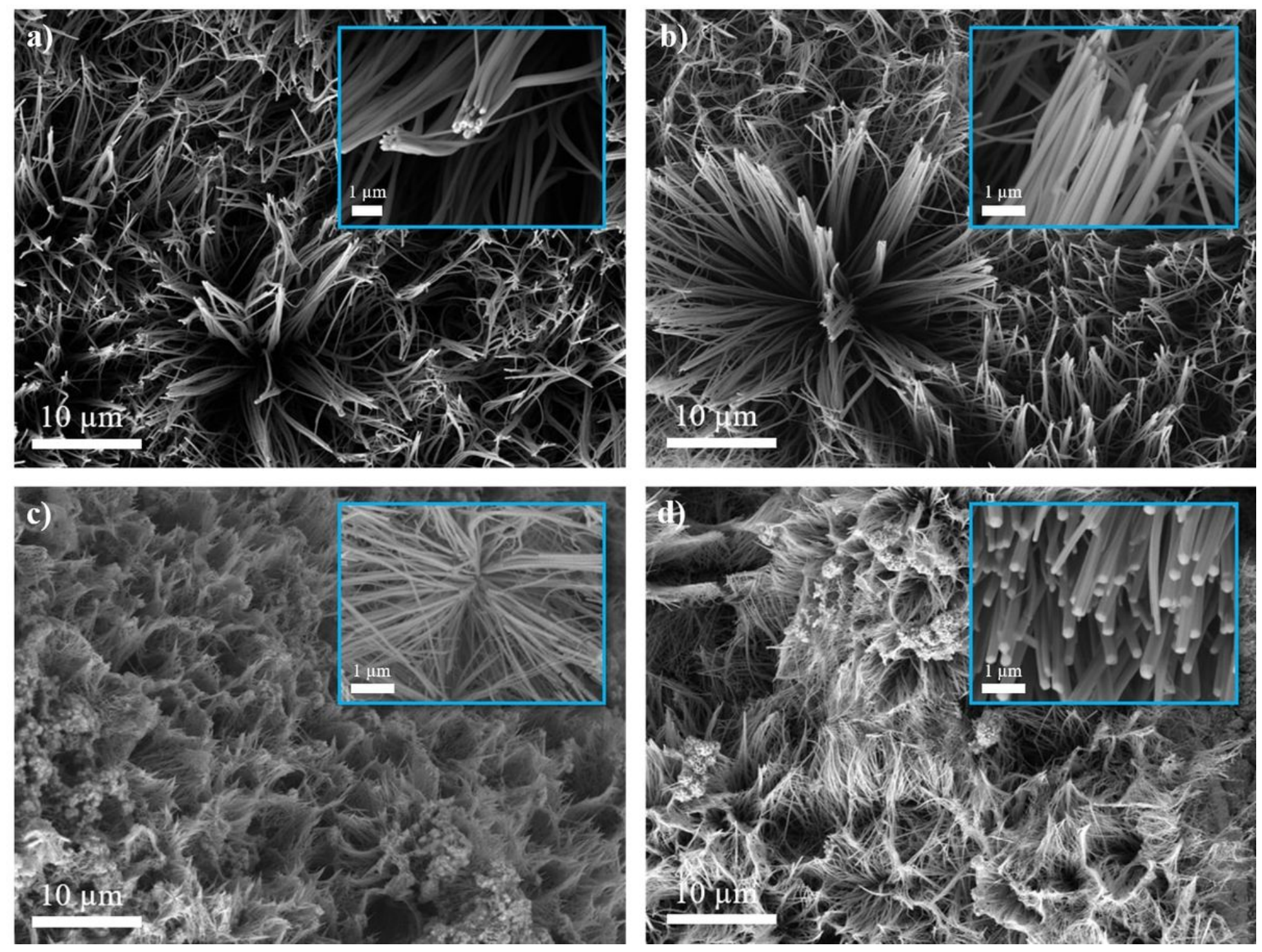

\section{Figure 3}

Fig. 3 shows the surface images of the ZnO NWs were obtained at different voltages such as 10, 20, 30 and $40 \mathrm{~V}$. As seen in the Fig. 3a, the nanoflower structures formed at an initial point of growth transformed to aligned NW structures. ZnO NWs have become thinner and denser structures with increasing voltage. When the applied voltage is $40 \mathrm{~V}$, there were linked and interpenetrated structures due to the length of the NWs as seen in Fig. 3d. Furthermore, micro cracks were observed on the surface due to oxygen evaluation during anodization at high voltage. 

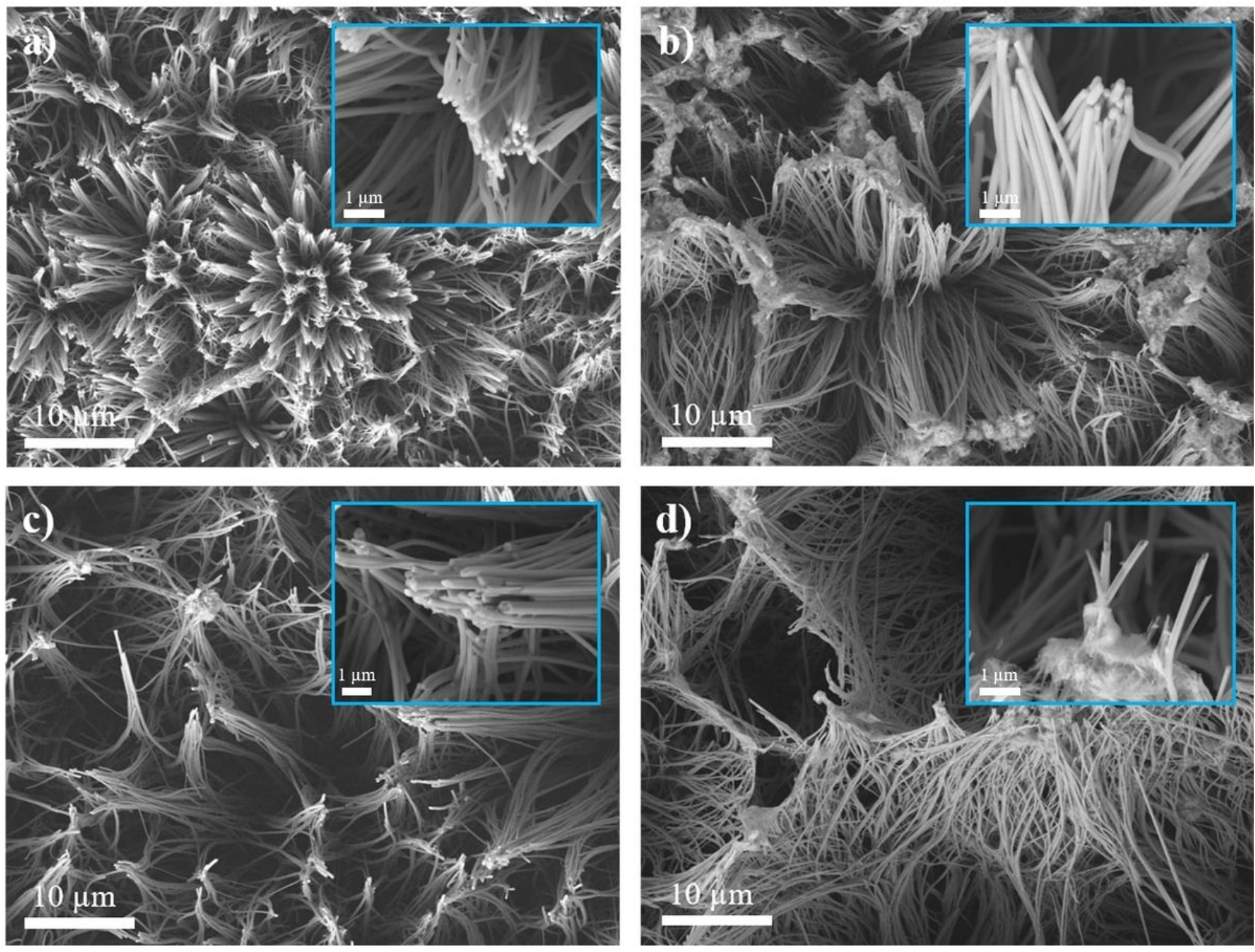

Figure 4

Fig. 4 indicates the effects of anodizing time on the morphology of $\mathrm{ZnO} N W s$. The results show that as the anodizing time increases, the thickness of the $\mathrm{ZnO}$ NWs decreases while the density increases. The hierarchical ZnO NWs structure has emerged after anodization for $60 \mathrm{~min}$. 


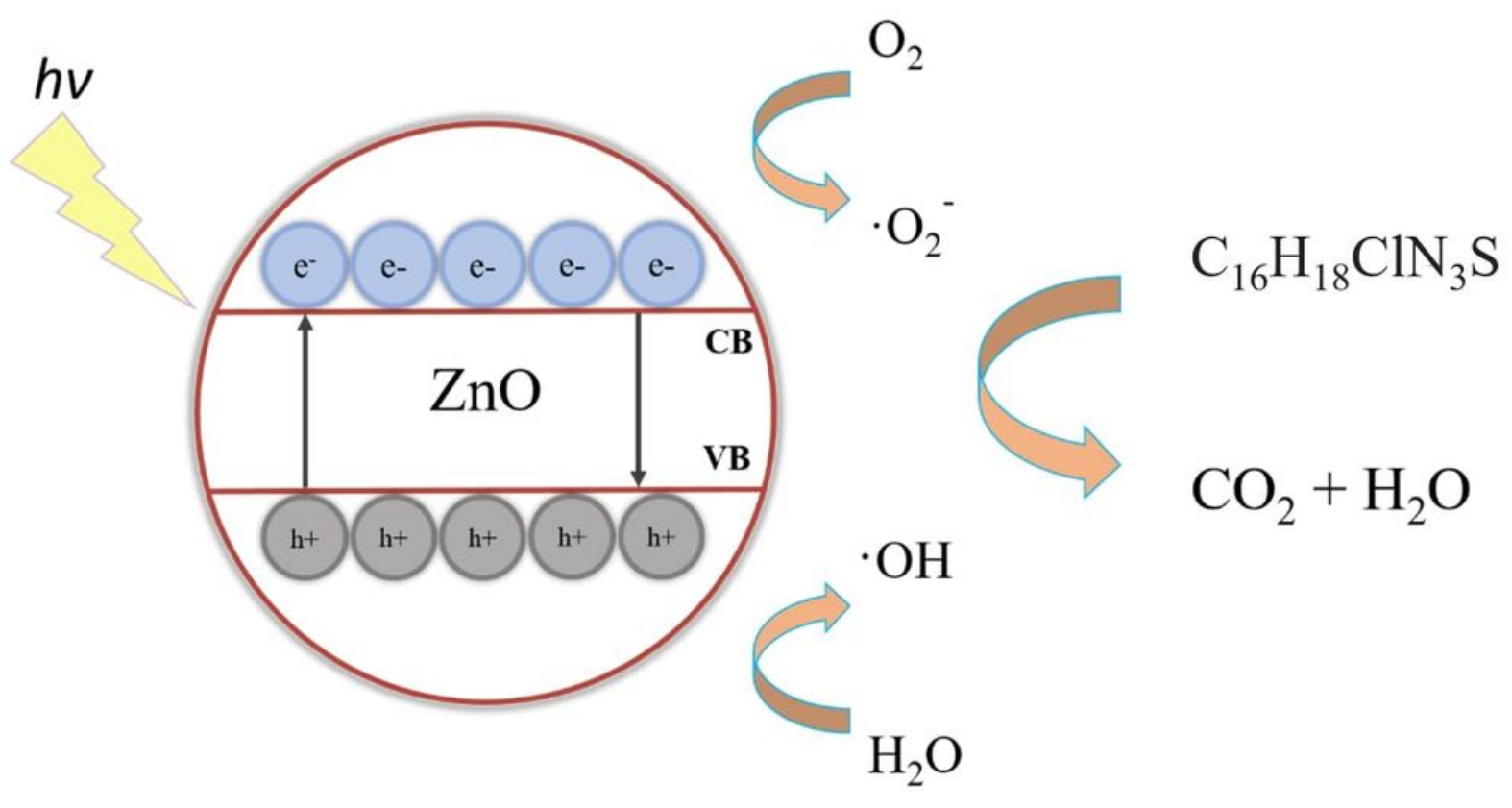

Figure 5

The photocatalytic mechanism of ZnO NWs with different morphological properties was shown in Fig. 5.
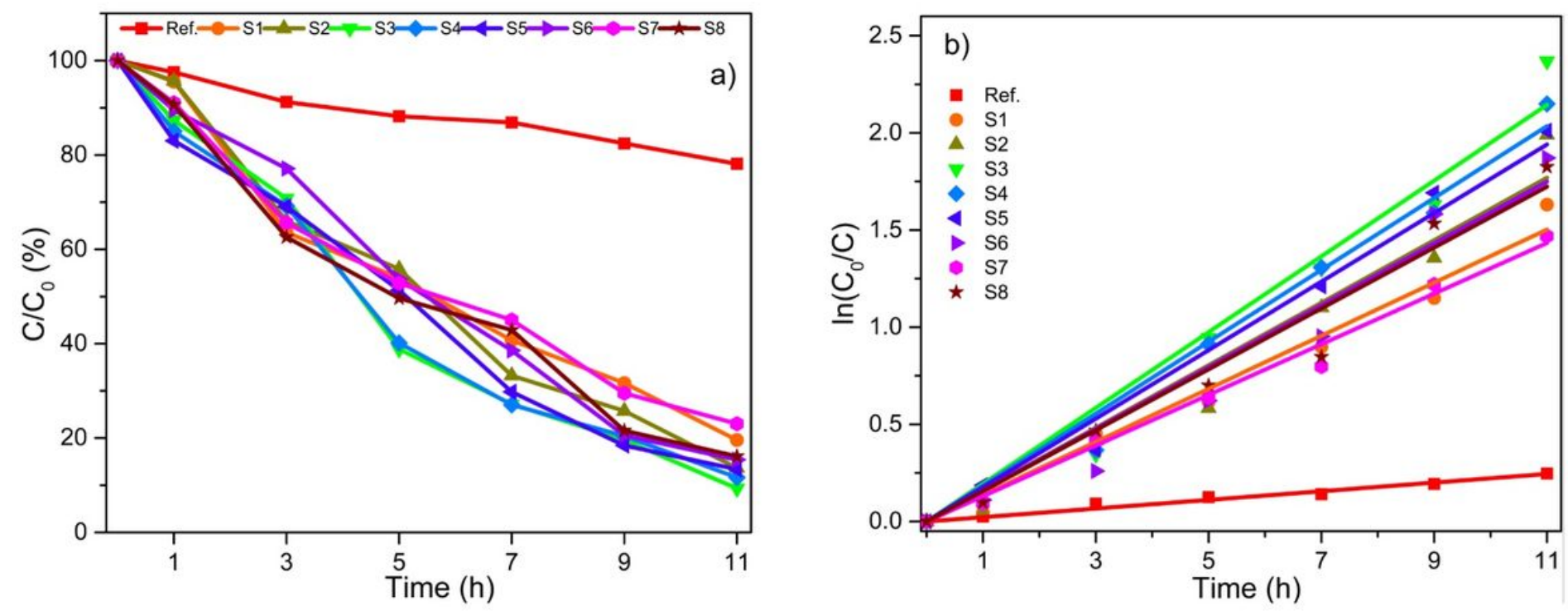

Figure 6

Fig. 6a shows the change in concentration of MB over 11 hours. The degradation efficiency, kinetic rate constant and determination coefficient parameters of the samples are given in Table 2 . The $k$ values obtained from the slope of the lines in Fig. $6 \mathrm{~b}$ show that the most enhanced photocatalytic degradation of MB was obtained with the $\mathrm{S} 3$ sample. 


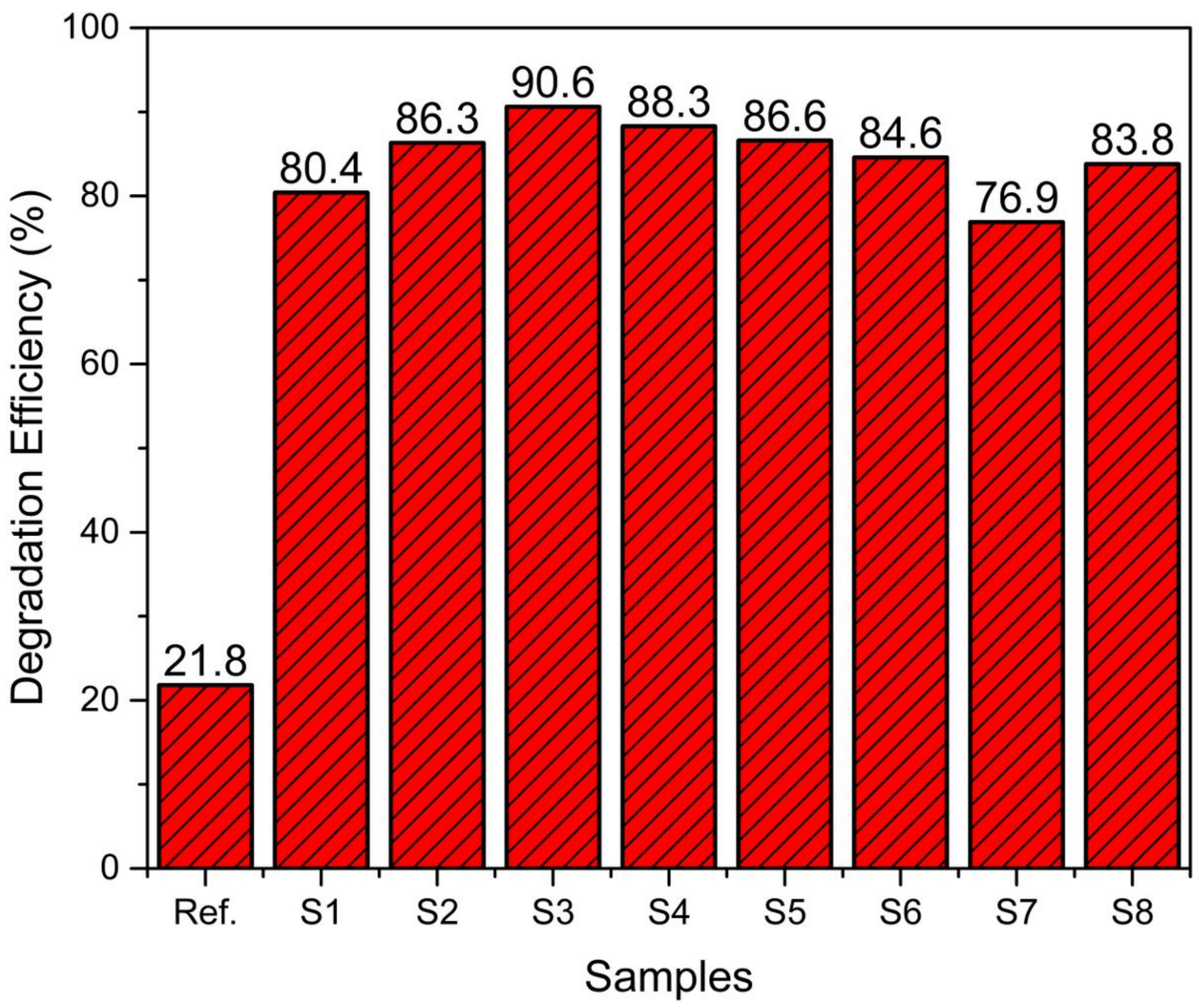

Figure 7

The degradation efficiencies of MB with an initial absorbance value of 0.695 at $664 \mathrm{~nm}$ by different samples were calculated for each sample. The results obtained are given in Table 2 and shown as a bar graph in Fig. 7. 


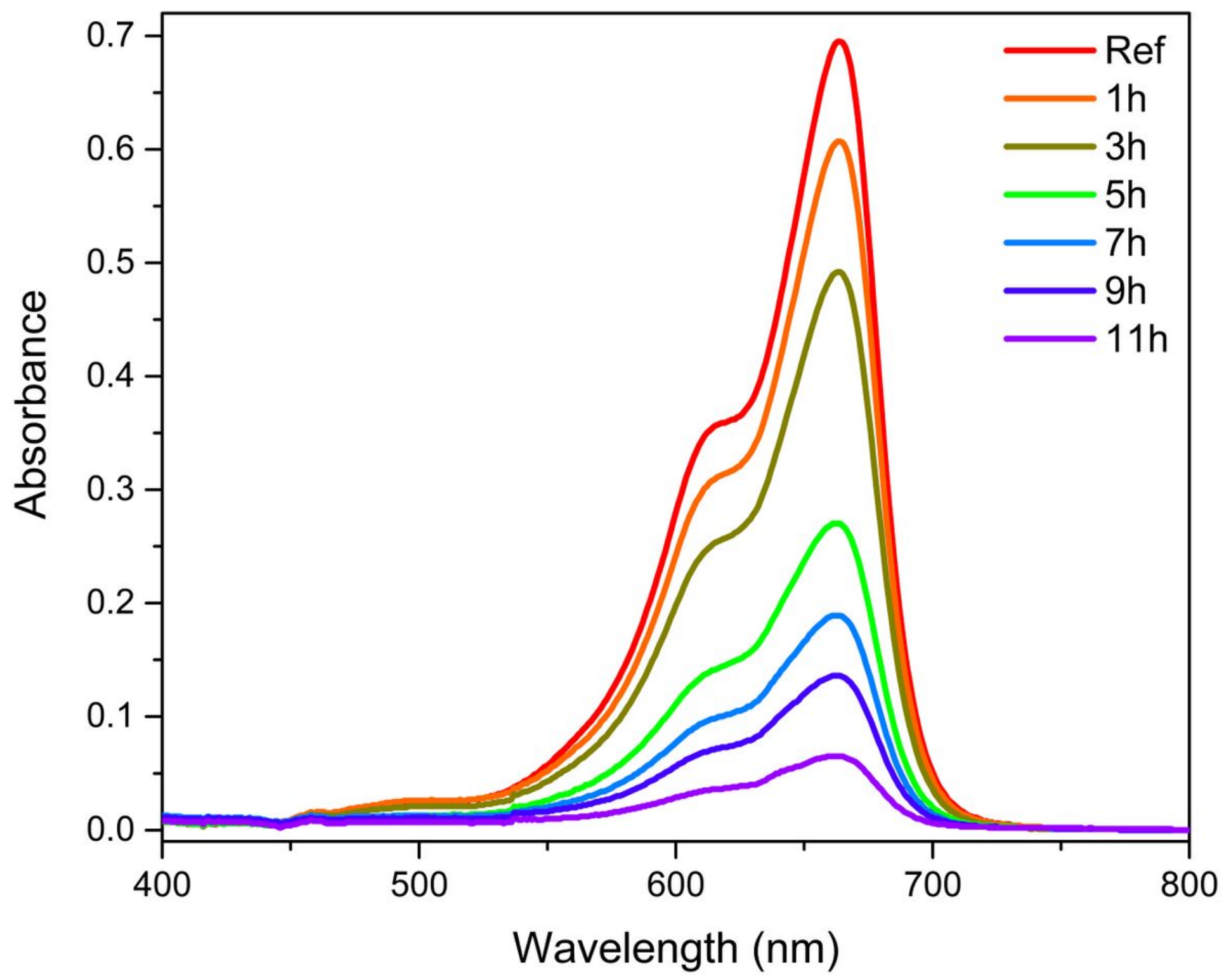

Figure 8

Absorption spectra of MB for sample S3 were drawn for different durations and are shown in Fig. 8. 